\title{
PENGEMBANGAN SITUS WEB SEBAGAI MEDIA INFORMASI DAN PROMOSI MENGGUNAKAN FRAMEWORK CODEIGNITER 3 (STUDI KASUS KSU MANDIRI SUKSES UMS)
}

\author{
Muhibah Fata Tika \\ Giovanny Dani Saputra \\ Fredianto \\ Dimas Aryo Anggoro \\ Program studi Informatika \\ Universitas Muhammadiyah Surakarta \\ 1200170156@student.ums.ac.id \\ 1200170159@student.ums.ac.id \\ 1200170173@student.ums.ac.id \\ dimas.a.anggoro@ums.ac.id
}

Naskah diterima 10 Juni 2020

Naskah direvisi 20 Juni 2020

Naskah diterima untuk publikasi 30 Juni 2020

\begin{abstract}
ABSTRAK
Perkembangan teknologi informasi di berbagai bidang terus mengalami kemajuan yang pesat. Berkembangnya teknologi informasi semakin menegaskan perannya yang begitu penting dalam memberikan kemudahan dalam menyelesaikan berbagai kegiatan manusia. Koperasi Serba Usaha Mandiri Sukses UMS adalah sebuah koperasi yang melayani dosen dan karyawan di ruang lingkup Universitas Muhammadiyah Surakarta. Dengan jumlah anggota lebih dari 600 orang dan terus bertambah, diperlukan sebuah sistem informasi berbasis web untuk memudahkan akses informasi bagi anggota dan calon anggota baru. Informasi yang disajikan di web ini meliputi profil koperasi beserta visi dan misinya, penjelasan tentang layanan yang dimiliki oleh koperasi, dan informasi pendaftaran calon anggota baru. Web ini akan dibangun menggunakan teknologi framework Codelgniter 3.
\end{abstract}

KATA KUNCI: codeigniter, profil perusahaan, sistem informasi, web

\section{PENDAHULUAN}

PHP adalah server-side scripting language yang digunakan untuk membuat situs web yang dinamis. Framework Codelgniter membantu pengembang membuat web lebih cepat dan mudah dengan menyediakan sebuah model dasar kerangka kerja yang dilengkapi dengan API, library, dan esktensi. Framework ini dibuat berdasarkan desain model Model, View, dan Controller (MVC). MVC biasanya membagi sebuah aplikasi web menjadi layer yang terpisah, sehingga bisa dianalisis dan diimplementasikan secara terpisah. MVC mengurangi kompleksitas dari desain arsitektural dan meningkatkan fleksibilitas kode [1].

Koperasi merupakan suatu badan usaha yang memiliki peranan yang sangat penting dalam menumbuhkembangkan potensi ekonomi rakyat serta mewujudkan kehidupan demokrasi, kebersamaan, kekeluargaan, dan keterbukaan [2]. Seiring dengan perkembangan teknologi yang melaju dengan pesat, koperasi pun semakin berkembang pula. Perkembangan koperasi di Indonesia mengalami pertumbuhan yang cukup menggembirakan, di mana secara kelembagaan, koperasi dalam periode 2007-2008 mengalami perkembangan dengan laju perkembangan sebanyak 5.171 unit atau tumbuh 3,45\%, selain itu jumlah koperasi yang aktif juga mengalami peningkatan sebanyak 3.931 unit atau 3,74\% [3].

Koperasi Serba Usaha Mandiri Sukses (KSU Mandiri Sukses) adalah koperasi dosen dan karyawan yang berada di lingkup Universitas Muhammadiyah Surakarta yang memiliki banyak produk layanan dan jasa.

Banyaknya jasa dan layanan yang disediakan oleh KSU Mandiri Sukses membuatnya membutuhkan sarana untuk berbagi informasi dan promosi. Oleh karena itu, diperlukan sebuah sistem informasi berbasis web untuk mengatasi permasalahan tersebut. Situs web tersebut nantinya dapat digunakan sebagai media informasi dan promosi KSU Mandiri Sukses.

\section{URAIAN KEGIATAN PENGABDIAN}

Pada kegiatan pengabdian ini ada beberapa tahapan yang dilakukan yaitu mengidentifikasi masalah yang dihadapi oleh mitra, menentukan bahan ataupun perlengkapan untuk menyelesaikan permasalahan mitra dan selanjutnya merancang 
solusi untuk memecahkan permasalahan dengan membuat desain sistem menggunakan metode waterfall [4] yang meliputi Analisa kebutuhan fungsional dan non-fungsional. Tabel 1 dan 2 mendeskripsikan detail dari Analisa kebutuhan tersebut.

1. Kebutuhan Fungsional

Table 1. Kebutuhan Fungsional

\begin{tabular}{|c|c|}
\hline Kategori & Kebutuhan Baru \\
\hline \multirow[t]{3}{*}{ Performance } & $\begin{array}{l}\text { Menyediakan komponen penting } \\
\text { saja dalam website yang } \\
\text { berhubungan dengan } \\
\text { perpustakaan. }\end{array}$ \\
\hline & $\begin{array}{l}\text { Mempergunakan semua } \\
\text { komponen pada laman website. }\end{array}$ \\
\hline & $\begin{array}{l}\text { Menggunakan bahasa dan istilah } \\
\text { yang mudah dimengerti. }\end{array}$ \\
\hline \multirow[t]{2}{*}{ Information } & $\begin{array}{l}\text { Memberikan data yang lengkap } \\
\text { pada tiap komponen dalam } \\
\text { website }\end{array}$ \\
\hline & $\begin{array}{l}\text { Melengkapi setiap dokumen yang } \\
\text { dibutuhkan oleh operator dalam } \\
\text { menjalankan website. }\end{array}$ \\
\hline Efficiency & $\begin{array}{l}\text { Mengefisiensikan waktu load } \\
\text { pada setiap komponen dalam } \\
\text { website. }\end{array}$ \\
\hline Control & $\begin{array}{l}\text { Melakukan pengawasan melalui } \\
\text { monitoring website secara rutin. }\end{array}$ \\
\hline Economics & $\begin{array}{l}\text { Memilih server dan domain } \\
\text { dengan kualitas bagus, namun } \\
\text { harga masih terjangkau. }\end{array}$ \\
\hline Service & $\begin{array}{l}\text { Melakukan peningkatan layanan } \\
\text { yang memudahkan proses } \\
\text { pemasukan data peminjaman } \\
\text { dan pengembalian buku dalam } \\
\text { website. }\end{array}$ \\
\hline
\end{tabular}

2. Kebutuhan Non Fungsional

Table 2. Kebutuha Non Fungsional

\begin{tabular}{|c|c|l|}
\hline No & $\begin{array}{c}\text { Kebutuhan } \\
\text { Perangkat Keras }\end{array}$ & \multicolumn{1}{|c|}{$\begin{array}{c}\text { Kebutuhan Perangkat } \\
\text { Lunak }\end{array}$} \\
\hline 1 & Komputer/Laptop & $\begin{array}{l}\text { Sistem Operasi } \\
\text { Sistem Operasi yang } \\
\text { digunakan yaitu } \\
\text { Windows 10. }\end{array}$ \\
\hline
\end{tabular}

\begin{tabular}{|c|l|l|}
\hline 2 & Prosessor Core 13 & $\begin{array}{l}\text { Apache } \\
\text { Merupakan web server } \\
\text { yang digunakan untuk } \\
\text { menjalankan aplikasi. }\end{array}$ \\
\hline 3 & RAM 4 Gb & $\begin{array}{l}\text { DBMS } \\
\text { MySql yang digunakan } \\
\text { untuk penyimpanan data- } \\
\text { data. }\end{array}$ \\
\hline 4 & $\begin{array}{l}\text { Media } \\
\text { penyimpan/Harddisk }\end{array}$ & $\begin{array}{l}\text { Bahasa Pemrograman } \\
\text { Framework yang dipakai } \\
\text { untuk membuat website } \\
\text { yaitu menggunakan } \\
\text { Codelgneter, CSS, dan } \\
\text { Bootstrap. }\end{array}$ \\
\hline 5 & Keyboard & $\begin{array}{l}\text { Web browser } \\
\text { Digunakan untuk } \\
\text { membantu akses ke } \\
\text { Internet yaitu Google } \\
\text { Chrome atau Mozilla } \\
\text { Firefox. }\end{array}$ \\
\hline & & $\begin{array}{l}\text { Text Editor } \\
\text { Visual Studio Code atau } \\
\text { Sublime merupakan text } \\
\text { editor yang digunakan } \\
\text { untuk membuat aplikasi. }\end{array}$ \\
\hline & & \\
\hline & & \\
& &
\end{tabular}

\section{METODE}

Untuk mengumpulkan data yang diperlukan, kami menggunakan metode observasi dan wawancara. Kami mewawancarai pengurus koperasi untuk mendapatkan informasi mengenai kebutuhan apa saja yang diinginkan termasuk fitur, dan layanan yang dimiliki [5].

Kemudian untuk mengembangkan web, kami menerapkan konsep siklus daur hidup perangkat lunak waterfall yang sudah digunakan secara luas [6]. Penyesuaian yang kami lakukan adalah sebagai berikut.

\section{Perencanaan}

Pada tahap ini kami melakukan observasi dan menentukan konsep situs web yang cocok sesuai dengan hasil wawancara sebelumnyaa.

\section{Analisis}

Pada tahap ini kami membuat daftar kebutuhan fungsional dan non-fungsional. Kebutuhan fungsional adalah fungsi-fungsi yang diharapkan ada di dalam situs web oleh pihak koperasi. Kebutuhan non-fungsional salah satunya yaitu penetuan teknologi yang akan digunakan untuk membuat situs web ini. Teknologi yang digunakan pada proyek ini yaitu framework Codelgniter 3. 
3. Desain

Setelah melakukan perencanaan dan analisis, kami menyusun rancangan tampilan situs web dan diagram kerjanya (use case). Berikut ini adalah rancangan use case-nya.

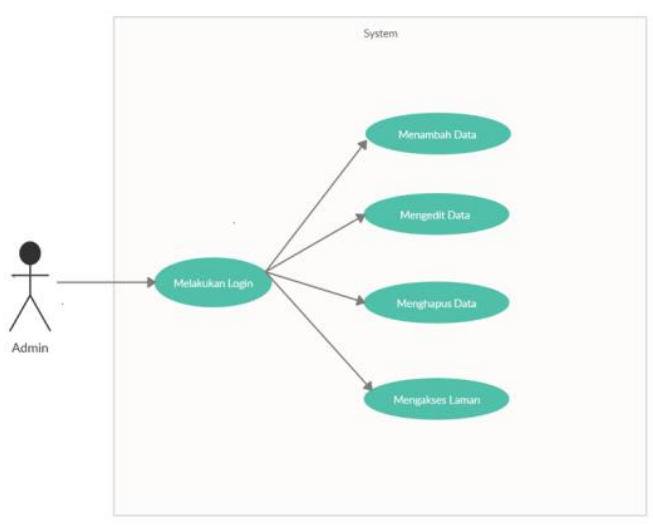

Gambar 1. Use Case Diagram

4. Implementasi

Pada tahap ini mulai dilakukan penulisan kode program situs web dengan berorientasi hasil perencanaan dan analisis.

\section{Pengujian}

Sebelum di-deploy ke hosting, telah dilakukan pengujian secara mandiri ketika proses koding berjalan. Proses ini merupakan pengujian secara offline di server localhost. Kemudian dilakukan pengujian kembali setelah web di-deploy dan online.

\section{Perawatan}

Pada tahap ini dilakukan pemantauan situs web apabila terdapat bug atau kendala lain. Jika kemudian ada keluhan atau ditemukan bug dalam situs web ini, maka akan segera diperbaiki.

\section{HASIL DAN PEMBAHASAN}

Proses pengerjaan yang memakan waktu sekitar satu bulan lebih menghasilkan sebuah situs web yang ringan dan sederhana, namun berfungsi dengan baik dan powerful. Situs web ini memiliki beberapa menu seperti Home, Layanan, Tentang Kami, dan Kontak. Gambar 2 merupakan tampilan screenshot-nya. Laman ini merupakan halaman utama yang tampil ketika situs web di akses. Terdapat beberapa informasi dasar yang ditampilkan seperti slider, daftar layanan pada sidebar, dan bagian utama yang berisi daftar artikel. Menu ini berisi daftar produk dan jasa yang disediakan oleh koperasi seperti simpan pinjam syariah, swalayan, rental mobil, pengadaan toga, fotokopi, dan kredit barang.

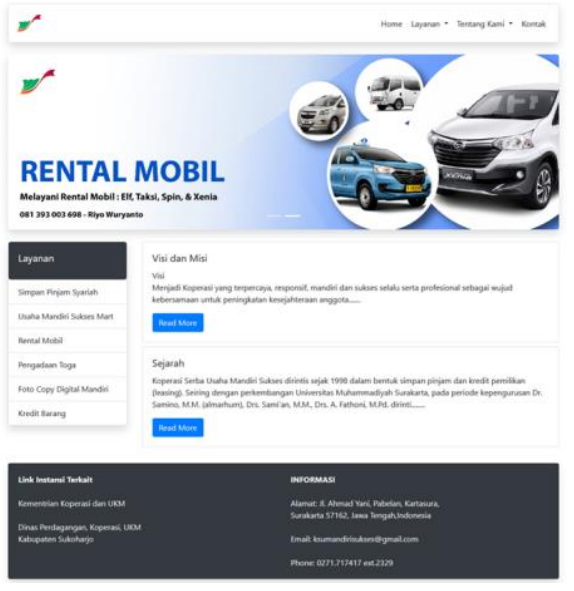

Gambar 2. Home

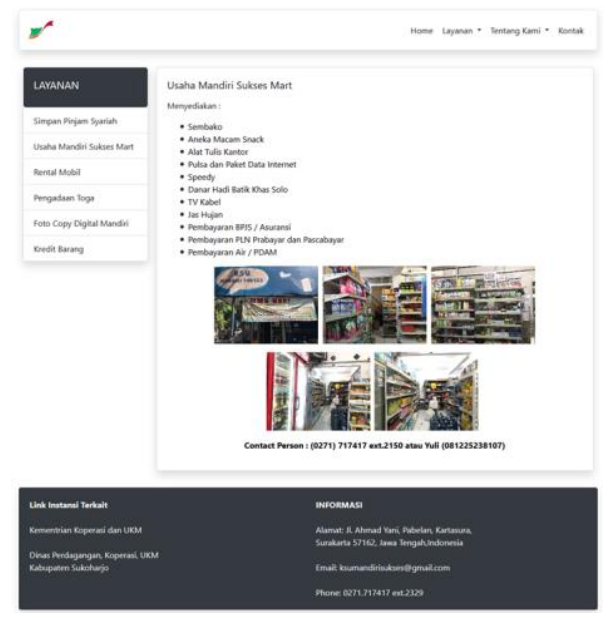

Gambar 3. Layanan 


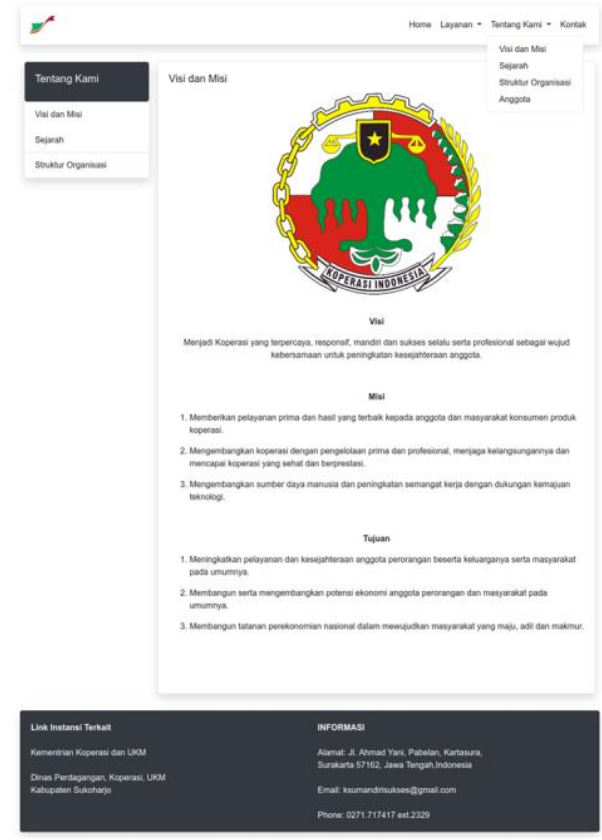

Gambar 4. Tentang Kami

Menu ini berisi informasi mengenai koperasi seperti visi dan misi, sejarah, dan struktur organisasi.

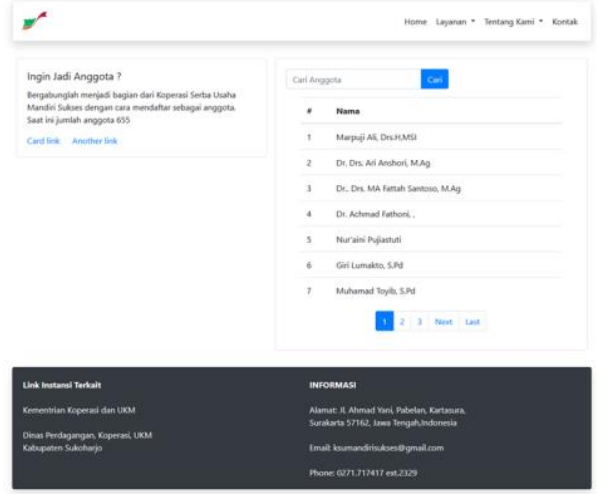

Gambar 5. Anggota

Pada bagian ini juga terdapat sub-menu Anggota yang menampilkan nama-nama anggota koperasi dan sebuah tautan pendaftaran anggota baru.

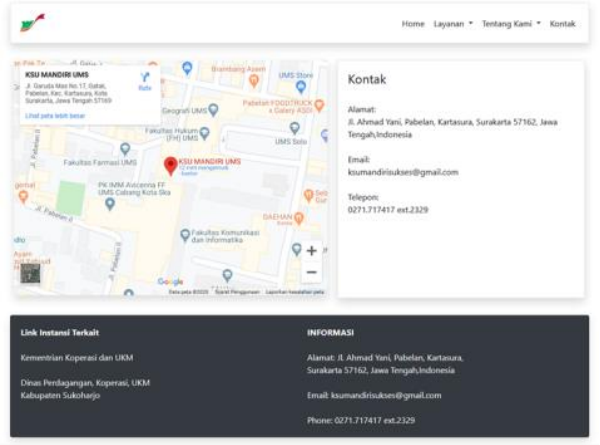

Gambar 6. Kontak
Terakhir adalah menu Kontak, menu ini berisi informasi alamat dan peta kantor, surel, dan nomor telepon yang bisa dihubungi.

Situs web ini memiliki fungsi dasar sebagai media penyebaran informasi dan media promosi untuk KSU Mandiri Sukses. Kekurangan di situs ini adalah sistem pendaftaran anggota baru yang hanya menyematkan tautan Google Form daripada menyediakan portal pendaftaran secara mandiri. Hal ini terjadi atas permintaan pihak koperasi yang menginginkan sistem pendaftaran melalui Google Form saja.

\section{KESIMPULAN}

Kegiatan ini bertujuan untuk menciptakan sebuah platform promosi untuk mendukung perkembangan KSU Mandiri Sukses Universitas Muhammadiyah Surakarta. Selain itu, keseluruhan proses pembuatan situs web ini sangat berarti bagi kami guna menambah pengalaman dalam melayani masyarakat.

Dari kegiatan yang telah kami laksanakan, dapat ditarik kesimpulan sebagai berikut.

1. Memberi manfaat bagi kami karena dapat mengimplementasikan ilmu yang didapat di perkuliahan.

2. Memberi kemudahan bagi anggota maupun calon anggota baru dan masyarakat untuk mendapatkan informasi mengenai KSU Mandiri Sukses Universitas Muhammadiyah Surakarta.

Selanjutnya situs web ini akan diserahkan kepada pihak koperasi agar dapat dikelola secara mandiri. Dalam proses pembuatannya, kami berorientasi pada kemudahan dalam pengoperasiannya. Jika di masa depan ada pihak yang ingin mengembangkan situs web ini agar menjadi lebih baik, seluruh codebase dari situs web ini telah kami unggah ke repositori GitHub yang aksesnya telah dilimpahkan kepada pihak koperasi.

\section{DAFTAR PUSTAKA}

[1] M. Laaziri, K. Benmoussa, S. Khoulji, dan M. L. Kerkeb, "A Comparative study of PHP frameworks performance," Procedia Manufacturing, vol. 32, hlm. 864-871, 2019, doi: 10.1016/j.promfg.2019.02.295.

[2] E. Rahmawati, T. Retnasari, dan D. Arifianto, "Sistem Informasi Simpan Pinjam 
Koperasi Berbasis Web," Jurnal Teknik Komputer Amik Bsi, vol. 2, no. 2, hlm. 8388 , 2016.

[3] Aryanto, A., \& Irianto, T. (2013). Pembuatan Sistem Informasi Perpustakaan Smp Muhammadiyah 7 Surakarta. Journal Speed Sentra Penelitian Engineering Dan Edukasi, Vol 5 No $1,15-20$.

[4] Dian Gigih Indrawati (2016). Sistem Informasi Simpan Pinjam Pada Koperasi Sedia Kec.Tangen Menggunakan Php Mysql Dan Sms Gateway. Eprints.ums.ac.id

[5] Krisna Satria, Hernawan Sulistyanto, Jatmiko. (2013). Sistem Informasi Penjualan Dan Simpan Pinjam Pada Koperasi Teh Tambi Wonosobo Menggunakan Lazarus Dan Mysql. Eprints.ums.ac.id

[6] Jatmiko, Yusuf S.N, Eka Yudi N. (2012). Rancang Bangun Sistem Aplikasi Transaksi Koperasi Yudi Jaya Wonosobo. Simposium Nasional RAPI XI FT UMS. 